\title{
The Relationship between Anxiety, Depression and Self-esteem in Adolescents with Learning Disability
}

\author{
Parita Shah ${ }^{1}$ \\ ${ }^{1}$ Student of Masters in Clinical Psychology, Maniben Nanavati Women's College, Mumbai \\ Corresponding author: Parita Shah \\ Email - paritaarpita@gmail.com
}

\begin{abstract}
Background: The purpose of this study was to find out the relationship between anxiety, depression and self-esteem in adolescents with learning disabilities. It was hypothesized that there will be significant positive correlation between depression and anxiety in adolescents with learning disability and significant negative correlation between self-esteem and depression and between self-esteem and anxiety in adolescents with learning disabilities.

Methodology: The sample consisted of 70 adolescents with learning disabilities. The age of the participants ranged from 13-18 years. All the participants were taken from English medium schools and college. The participants completed surveys containing Beck Depression Inventory- II, Beck anxiety Inventory and Rosenberg self-esteem scale.

Results: The data was analyzed using Person correlation coefficient. The results indicated the significant positive correlation between anxiety and depression with $r$ value $=0.651$ and $p<0.01$, significant negative correlation between depression and self-esteem with $r$ value $=-0.710$ and $p<0.01$ and significant negative correlation between anxiety and self-esteem with $r$ value $=-0.534$ and $p<0.01$.

Conclusion: It can be concluded that was there is significant relationship among the three variables in adolescents with learning disabilities.
\end{abstract}

Keywords: Learning disabilities, anxiety, depression, self-esteem.

(Paper received $-30^{\text {th }}$ November 2019, Peer review completed $-22^{\text {nd }}$ December 2019 )

(Accepted $-26^{\text {th }}$ December 2019)

\section{INTRODUCTION}

Learning Disabilities can affect at least $5-15 \%$ of school aged children and $4 \%$ of adults approximately [1]. Earlier people did not have knowledge about learning disabilities. With increasing awareness about it, more children are now getting diagnosed with it and therefore coming out more in number. Learning disabilities are the problems which affect the brain's ability to receive, process, analyse and store information. These problems affect children by making learning difficult for them [2]. There are different kinds of learning disabilities and most children are affected by more than one of them. Learning disabilities leads to difficulty in reading, writing, spelling or solving math problems.

There are number of academic and personal problems which adolescents with Learning Disabilities face. Adolescents with Learning disabilities have difficulty in performing tasks related to reading, writing which other people of their age can do very easily. Because of this, they often do not score well in exams any this affects their self-esteem. They are also isolated by their peers or are bullied. Also, they are pressurized from their parents and teachers to perform well and they face harsh criticisms from everyone. These things lead 
to self-doubt in children and they tend to feel depressed most of the time since they have difficulty in doing the task which is most crucial for their age. They also get anxious in many social and academic situations. Bandura, had once said that, "self-belief does not necessarily ensure success, but self-disbelief assuredly spawns failure". This self-disbelief is normally seen in children with Learning Disability. Many researches indicate that learning disabilities can lead to low self-esteem, high depression and anxiety in children or adolescents suffering from it. Students with Learning Disabilities have lower self-concepts, lower selfperception and lower self-esteem [3-5].

\section{Concepts used in study \\ Learning Disabilities}

According to Learning Disabilities Association of Canada (2015), "Learning Disabilities refer to a number of disorders which may affect the acquisition, organization, retention, understanding or use of verbal or nonverbal information". These disorders affect learning in individuals who otherwise demonstrate at least average abilities essential for thinking and/or reasoning. As such, learning disabilities are distinct from global intellectual disabilities. One or more psychological processes related to learning, in combination with otherwise average abilities essential for thinking and reasoning result in this disorder. Learning disabilities are specific not global impairments and as such are distinct from intellectual disabilities. According to Diagnostic and Statistical Manual IV Text Revision (DSM-IV-TR, 2011), Learning disabilities can exist as disorder of reading, math, or written expression [6]. Kaplan and Sadock (2015) 3 main types of Learning disabilities and they are [7]:-

1. Dyslexia - It is characterized by difficulty in recognizing words, inaccurate and slow reading, reading difficulty with spelling and poor communication. In DSM-5 dyslexia is called Specific Learning disorder with impairment in reading and dyslexia is used as an alternate term.

2. Dysgraphia - In DSM-5, it is called Specific Learning Disability with impairment in written expression. It is marked by significantly low level of writing skills. There are problems with spelling, grammar and punctuation accuracy and there is no clarity or organization of written expression.

3. Dyscalculia - In this, there is difficulty in learning and remembering numerals, problems with remembering basic facts about numbers and computation is slow and inaccurate. In DSM-5, it is called Specific Learning Disability with impairment in mathematics.

\section{Depression}

Adolescents with Learning Disabilities face many other problems when compared to other children of their age. Adolescents with learning disabilities often have problems that go far beyond those experienced in reading, writing, math, memory, or organization. For many, strong feelings of frustration, anger, sadness, or shame can lead to psychological difficulties such as anxiety, depression, or low self-esteem, as well as behavioural problems such as substance abuse or juvenile delinquency. Raskind, an expert in the field of learning disabilities said, "Unfortunately, these problems can be far more devastating than the academic challenges themselves. Although the severity and duration of a child's psychological difficulties may vary as she grows up, such issues can find their way into and through adulthood [8]. Sideridis found direct positive paths linked performance avoidance to depression, negative affect and anxiety; negative affect in his study [9]. Tam and Hawkins aimed to study Self-Concept and Depression Levels of students with Dyslexia in Singapore. Results of this study showed that proportion of students who rated academic self-concept were different from those who rated it negatively. A negative correlation was found between self-concept and depression [10].

Depression is marked by feelings of sadness. For more than 30 years, research has been done on depression. In 1970s there were three reasons why children with Learning Disabilities were believed to have greater risk for depression. These reasons were having low self-esteem, scoring less in academic achievement tests and having some sort of neurological difficulties [11].

\section{Anxiety}


Depression often has overlapping symptoms with anxiety [12-13]. These problems can become chronic or recurrent and lead to substantial impairments in an individual's ability to take care of his or her everyday responsibilities. At its worst, depression can lead to suicide. Anxiety is typical reaction to stress, an unpleasant emotional response evoked by imagined or real threat and danger. Anxiety can be defined as "a future oriented and global response involving both cognitive and emotional components, in which individual is inordinately apprehensive, tense and uneasy about the prospect of something terrible happening" [14]. According to Kazdin, "anxiety can be defined as an emotion characterised by feelings of tension, worried thoughts and physical changes like increased blood pressure [15]". Renee Grinnell (2018), defined "anxiety as feelings of dread or worry, often accompanied by physical signs of arousal, which are a normal reaction to stress." DSM-IV-TR defined "anxiety as the apprehensive anticipation of future danger or misfortune accompanied by a feeling of dysphoria or somatic symptoms of tension. The focus of anticipated danger may be external or internal."

Adolescents with learning disability may have symptoms of anxiety as they have to face tasks of reading, writing etc., and because of these tasks, they may experience unpleasant feelings and fears and perceive it as threat or danger. Anxiety disorders in normative samples of school-aged children are considered widespread with prevalence rates ranging between 10 and 21\% [16] and research also indicates that youth with Learning Disabilities experience higher levels of anxiety. Custodero and Lyn, discovered through their research that students with Learning Disabilities have statistically significant difference on trait and test scores when compared to students without disabilities [17].

Galleos, Langley and Villegas did study to know about anxiety, depression and coping skills among Mexican school children with and without learning disabilities and concluded that greater numbers of children with learning disabilities are at risk of anxiety and depression as compared to children without learning disabilities [18].

\section{Self-esteem}

Alesi, Rappo and Pepi did a study on Depression, Anxiety in school and Self-esteem in children with Learning Disability. Results indicated that children with Learning disability have higher level of depression and school anxiety and also low self-esteem at school than children with typical learning [19]. A research indicated that children with Learning Disability were either highly anxious or less anxious and children with high self-esteem had low academic anxiety compared to children with moderate self-esteem [20].

Rosenberg defines self-esteem "as totality of the individual's thoughts and feelings with reference to himself as an object." Another definition of Self-esteem was referred as "an individual's sense of his or her value or worth, or the extent to which a person values, approves of, appreciates, prizes, or likes him or herself" [21]. There is much research that shows that children who have learning disabilities are at risk for having lower self-esteem and self-worth than that of their peers [19, 22-23]. From an early age, children compare themselves with others in areas such as academics, the ability to make and keep friends, and athletic prowess. "Children with learning disabilities may judge themselves as 'stupid', 'slow' or 'dumb', based on academic comparisons with other children" [24]. Low self-esteem can affect the child badly and also hamper his or her future. With low self-esteem, there is a possibility that child might get many other psychological issues.

\section{METHODOLOGY}

\section{Aim}

To study the relationship between anxiety, depression and self-esteem in adolescents with learning disabilities.

\section{Objectives}

1. To study the relationship between Anxiety and Depression in adolescents with Learning Disability.

2. To study the relationship between Anxiety and Self-esteem in adolescents with Learning Disability. 
3. To study the relationship between Self-esteem and Depression in adolescents with Learning Disability.

\section{Hypotheses}

The following hypotheses were investigated:

1. There is a significant positive correlation between Anxiety and Depression in Adolescents with Learning Disability.

2. There is a significant negative correlation between Anxiety and Self-esteem in Adolescents with Learning Disability.

3. There is a significant negative correlation between Self-esteem and Depression in Adolescents with Learning Disability.

\section{Variables}

Variables investigated were -
a. Anxiety
b. Depression
c. Self-Esteem

\section{Operational definition}

1. Adolescents with Learning Disability- are children from age 13-18 years who have been diagnosed with Learning Disability and have LD certificate.

2. Anxiety - as measured by the scores obtained on Beck Anxiety Inventory by Aaron Beck in year 1988.

3. Depression - as measured by the scores obtained on Beck Depression Inventory $2^{\text {nd }}$ edition by Aaron Beck in year 1996.

4. Self-esteem- as measured by scores obtained on Rosenberg Self-esteem Scale developed by Dr. Morris Rosenberg in year 1965.

\section{Participants}

The sample consisted of adolescents within the age range of 13-18 years from_different schools and colleges in Mumbai who were diagnosed with Learning Disability. The sample of 70 adolescents with learning disabilities were taken. Purposive sampling method was used for data collection.

\section{Inclusion criteria}

1. Adolescents should be diagnosed with Learning disability and should have LD certificate.

2. Adolescents should be between age range of 13-18 years.

3. Adolescents should have fluency of English language.

\section{Exclusion criteria}

1. Adolescents from any other medium except English medium will not be part of the study.

\section{Tools}

1. Rosenberg Self-Esteem Scale: This scale was developed by Rosenberg in 1965 to measure selfesteem. It is a 10 items scale and it measures global self-worth by measuring both positive and negative feelings. All items in the scale are answered using 4-point Likert scale ranging from strongly agree to strongly disagree. Scoring of the scale involves addition of scores and reverse scores of items as pertaining to the scoring instructions of the scale. The Rosenberg Self-Esteem Scale has internal consistency reliability of 0.77 and minimum coefficient of reproducibility of at least 0.90 [25]. Test-retest reliability of 2 weeks interval was found to be 0.87 and 7 months interval was calculated 0.63 [26-27]. 
2. Beck Anxiety Inventory (BAI): This scale was developed by Aaron Beck to measure anxiety in 1988 and its revised manual was published in 1993. It is a 21 item scale with Likert scale ranging from 0-3. Total score obtained on BAI between 0-21 indicate very low anxiety, the score between 22-35 indicate moderate level of anxiety and the score above 35 indicate severe anxiety. Test-retest reliability of Beck Anxiety was found 0.67 and internal consistency was found 0.94 [28]. For validity, it was found that BAI moderately correlated with revised Hamilton rating scale i.e., 0.51 and mildly correlated with Hamilton Depression Rating Scale i.e., 0.25 [29]. A research was done by Steer RA et al. on BAI used on adolescents in the year 1995. Results of this research supported the use of BAI for evaluating self-reported anxiety in adolescents [30].

3. Beck Depression Inventory II (BDI-II): It was developed by Aaron Beck in 1996 and is a 21 item self-report questionnaire used to measure depression. The BDI-II is rated on 4 point Likert scale ranging from $0-3$ based on severity of each item. It is widely used indicator of severity of depression. Total score obtained on BDI-II between 0 to 13 indicate minimal depression, the score between 14 to 19 indicate mild depression, the score between 20 to 28 indicate moderate depression and the score above 28 indicate severe depression [31]. BDI-II has good psychometric properties. The internal consistency is found to be 0.90 and the test-retest reliability ranged from $0.73-0.96$. The criterion based validity of BDI-II shows good sensitivity and specificity for detecting depression [32].

\section{RESULTS}

The main aim of the study was to find the relationship between self-esteem, anxiety and depression in adolescents with learning disabilities. The sample size was 70 with both male and females. After data collection, next step was to analyse data the statistically and interpret the findings at both statistical and theoretical levels. Collected data has been presented in a table form after calculating basic statistical factors like mean and standard deviation (SD) and correlation and regression analysis.

Table 1: Descriptive statistics table of Variables

\begin{tabular}{|l|c|c|c|}
\hline & Mean & Std. Deviation & $\mathrm{N}$ \\
\hline Rosenberg & 17.42 & 5.794 & 69 \\
\hline BAI & 17.97 & 11.729 & 69 \\
\hline BDI2 & 18.97 & 11.306 & 69 \\
\hline
\end{tabular}

The statistical properties of the variable are depicted in Table 1 for the entire sample. The mean for Rosenberg self-esteem scale was 17.42 with SD 5.794. The mean for Beck Anxiety Inventory was 17.97 with SD 11.729. The mean for Beck's Depression Inventory-II was 18.97 with SD 11.306.

A correlation analysis was done to find out if self-esteem, anxiety and depression are significantly related to adolescents with learning disabilities (as reported in Table 2). The Pearson correlation was done to find out the correlation. The Pearson correlation coefficient, $r$, can take range of values from +1 to -1 . A value of 0 indicates that there is no association between the two variables. A value greater than 0 indicates a positive association, that is, as value of one variable increases, so does the value of other variable. A value less than 0 indicates negative association; that is, as the value of one variable increases, the value of the other variable decreases. 
Table 2: Correlation Analysis between Self Esteem, Depression and Anxiety

\begin{tabular}{|c|c|c|c|c|}
\hline \multicolumn{5}{|c|}{ Correlations } \\
\hline & & Rosenberg & BAI & BDI2 \\
\hline \multirow[t]{3}{*}{ Pearson Correlation } & Rosenberg & 1.000 & -0.534 & -0.710 \\
\hline & BAI & -0.534 & 1.000 & 0.651 \\
\hline & BDI2 & -0.710 & 0.651 & 1.000 \\
\hline \multirow[t]{3}{*}{ Sig. (2-tailed) } & Rosenberg & & .000 & .000 \\
\hline & BAI & .000 & & .000 \\
\hline & BDI2 & .000 & .000 & \\
\hline \multirow[t]{3}{*}{$\mathrm{N}$} & Rosenberg & 69 & 69 & 69 \\
\hline & BAI & 69 & 69 & 69 \\
\hline & BDI2 & 69 & 69 & 69 \\
\hline
\end{tabular}

A correlational and predictive trends of self-esteem, anxiety and depression in adolescents with learning disabilities were explored. There was a significant positive correlation between depression and anxiety in adolescents with learning disabilities. As given in the table 2 , the $\mathrm{r}$ value was 0.651 which was significant at 0.01 level, i.e. $(r=0.651, p<0.01)$. Depression was negatively correlated with self-esteem in adolescents with learning disabilities. As given in the table 2 , the $r$ value was -0.710 which was significant at 0.01 level, i.e. $(\mathrm{r}=-0.710, \mathrm{p}<0.01)$. Anxiety was negatively correlated with self-esteem in adolescents with learning disabilities. As given in table 2 , the $r$ value was -0.534 which was significant at 0.01 level, i.e. $(r=-0.534$, $\mathrm{p}<0.01$ ). Thus the result revealed that there is association between depression, anxiety and self-esteem in adolescents with learning disabilities. Thus the hypotheses that there is significant positive correlation between depression and anxiety in adolescents with learning disabilities, there is significant negative correlation between anxiety and self-esteem in adolescents with learning disabilities and there is significant negative correlation between self-esteem and depression in adolescents with learning disabilities were validated.

Then a series of Regression Analysis were then conducted to estimate the extent to which depression and anxiety could be predicted from self-esteem.

Table 3: Regression Analysis for Self Esteem, Depression and Anxiety

\begin{tabular}{|l|c|c|c|c|}
\hline & $\mathrm{R}$ & $\mathrm{R} 2$ & $\mathrm{~F}$ & $\mathrm{Sig}$ \\
\hline BAI & 0.534 & 0.274 & 26.714 & 0.0001 \\
\hline BDI2 & 0.710 & 0.497 & 68.065 & 0.0001 \\
\hline
\end{tabular}

Details of this regression are provided in table 4.3. Results showed that self-esteem cam predict anxiety with significant accuracy $(\mathrm{R}=0.534, \mathrm{R} 2=0.285)$. The results also showed that self-esteem can predict depression with significant accuracy $(\mathrm{R}=0.710, \mathrm{R} 2=0.504)$. Thus, it seems that self-esteem can predict depression and anxiety in adolescents with learning disabilities. 


\section{DISCUSSION}

The research aimed at studying the relationship between depression, anxiety and self-esteem in adolescents with learning disabilities. For this purpose of the research, 70 participants were selected from schools and college using purposive sampling method who were suffering from Learning disability.

Learning disabilities is one of problems which many children and adolescents are encountering. There are types of learning disabilities like dyslexia, dysgraphia and dyscalculia and the person suffering from learning disabilities can have all of them, or two in combination or just one specific type of learning disability. Learning disabilities affects person's ability to receive, process, analyse and store information and this makes learning a bigger problem for people suffering from it. Learning disabilities in children and adolescents act as a barrier in academic progression as these children generally perform poorly as compared to their age children. Sometimes along with academics, there social life is also compromised and they face lot of pressure from teachers and their caregivers to perform well. This all, generally affects their self-esteem, increases anxiety and depression levels in them, and pushes them towards many problems like loneliness, social isolation, high stress etc. This can have adverse effects on them.

This research has three hypotheses and the first hypotheses states that there is a significant positive correlation between anxiety and depression in adolescents with learning disabilities. Second hypotheses states that there is a significant negative correlation between anxiety and self-esteem in adolescents with learning disabilities. And, the third hypotheses states that there is a significant negative correlation between self-esteem and depression in adolescents with learning disabilities. All the three hypotheses were validated by the results found.

Results are in line with results of study done by Alesi, Pepi and Rappo on depression, anxiety and selfesteem in children with learning disability. Their results indicated co-occurrence of anxiety and depressive symptoms in children with learning disability and low self-esteem in them.

These results were in line with past research done by Sati and Vig, that children with learning disability are either highly anxious or less anxious. Children with low anxiety had high self-esteem in contrast to children with moderate self-esteem.

During regression analysis, self-esteem was found to be predictor of anxiety and depression in adolescents with learning disabilities. This is in with the research done by Sati and Vig, mentioned above. It corroborates with the study done by Masselink, Roekel and Oldehinkel which indicated self-esteem as in early adolescence as predictor of depressive symptoms in late adolescence and early adulthood.

Adolescents with learning disabilities have great difficulty in learning and this learning can be done very easily by other adolescents of their age who don't have learning disabilities or any other disorders. This can affect their self-esteem greatly. It can also make them feel depressed and anxious. Adolescents with Learning disabilities have lot of reasons to feel anxious and depressed and have self-esteem issues. There can be situations, in which they need to learn, read, write and do mathematical calculation and they cannot do it easily or cannot do it at all because of learning disabilities. These situations can make them feel anxious almost all time as they face it regularly and also because they cannot cope with academics well. This all can also make them depressed as they have this disability. Also, factors like academic pressures, parental pressure, peer pressure affect them greatly and can really affect their self-esteem and make them feel anxious and depressed. They constantly strive to prove themselves and to cope and many times all their efforts end up in failure. There can be point in their life where they stop striving or putting efforts because of continuous failures. Also, adolescence is period of change. There are so many changes which happen physically, emotionally and cognitively and generally this proves to overwhelming for almost all adolescents. So this phase gets more complicated for people with learning disabilities as they not only have to cope with their disability but also other changes which are happening to them due to adolescence. This indeed affects lot of areas of their life. Therefore, all these reasons and many other reasons do affect self-esteem in adolescents with learning disability and make them feel depressed and anxious.

In present study, though all the three hypotheses were validated, mean of self-esteem score in adolescents with learning disability were found in normal range. Mean scores of anxiety and depression were not found 
in very high range (as seen in table 1). Reasons of it can be, since all these adolescents were diagnosed with learning disabilities, they might be getting remedial education which might help them in coping with their disability and therefore coping with other issues. Also, once the diagnosis of learning disabilities is received, these children and adolescents get benefits and extra help from schools which reduces the pressure on them to great extent. Since parents, teachers and other people start understanding their problems, negative consequences of this disability reduces as they start getting support and they are not misunderstood because of their disability.

Many studies prove that people with Learning disabilities are at high risks of suicide. Existential theory for anxiety stated that anxiety is response to personal void which person feels when he finds his existence purposeless. Also in psychodynamic theory, Freud explained anxiety as signal to presence of danger in the unconscious. This proves that adolescents with learning disability face anxiety.

The results can also be corroborated with Maslow's hierarchy of needs in theoretical perspectives which suggested that till the lower level needs are not satisfied, person won't reach higher level needs. Self-esteem comes is higher level needs. In adolescents with learning disability, their basic needs of protection is threatened as there is threat to bright future, threat to present situation, basic abilities of reading and writing are fared well and because of this, they can't reach to high levels of self-esteem. Also, according to Selfdetermination theory, person achieves high self-esteem when basic needs or psychological nutrients of life are in balance. In adolescents with learning disabilities, their basic needs are not in balance and therefore generally their self-esteem is found very high.

\section{Limitations}

The constricted nature of the sample size is one of the biggest limitation of the study. Research consisted of participants only between age 13-18 years and it is a very limited age range. The study was only conducted only in three schools and one college located in Mumbai and therefore it is difficult to generalize the result of the research. Study included self-reported questionnaires and there are chances that participants would have given socially desirable answers and this could bias the results. Other factors affecting adolescents like family dynamics, peer relations, financial status, severity of child's condition, teacher-student relation etc., were not taken into consideration. Comorbidity with any other disorder was not taken into consideration. Any stressors or extraneous variables like home or school environment were not controlled. Any confounds present, if any, would affect the statistical power of study overall.

\section{CONCLUSIONS}

Results obtained were in line with hypotheses. Significant positive correlation was found between anxiety and depression in adolescents with learning disabilities. Significant negative correlation was found between self-esteem and anxiety in adolescents with learning disabilities. Significant negative correlation was found between self-esteem and depression adolescents with learning disabilities. Regression was done after correlation was found in which self-esteem was found to be predictor of anxiety and depression in adolescents with learning disability. Overall, relationship of all three variables i.e., anxiety, depression and self-esteem in adolescents with learning disabilities, was found to be significant. Data supported the hypotheses and it was in line with many previous researches and with few theories.

\section{REFERENCES}

1. American Psychiatric Association. Diagnostic and statistical manual of mental disorders. BMC Med 2013;17:133-7.

2. Sorour AS, Mohamed NA, El-Maksoud MM. Emotional and behavioral problems of primary school children with and without learning disabilities: A comparative study. J Educ Pract 2014;5(8):1-1. 
3. Grolnick WS, Ryan RM. Self-perceptions, motivation, and adjustment in children with learning disabilities: A multiple group comparison study. J Learning Disabil 1990;23(3):177-84.

4. Klassen RM. Using predictions to learn about the self-efficacy of early adolescents with and without learning disabilities. Contemp Educ Psychol 2007;32(2):173-87.

5. Rosenthal JH. Self-esteem in dyslexic children. Acad Ther 1973;9(1):27-39.

6. American Psychiatric Association. Diagnostic and statistical manual of mental disorders (DSM-5®). American Psychiatric Pub; 2013.

7. Eggen PD, Kauchak D. Educational psychology. Prentice hall; 1999.

8. Wong B, editor. Learning about learning disabilities. Elsevier; 2011.

9. ValÅs H. Students with learning disabilities and low-achieving students: Peer acceptance, loneliness, selfesteem, and depression. Soc Psychol Educ 1999;3(3):173-92.

10. Tam HC, Hawkins R. Self-concept and attributional style for academic performances of students with dyslexia in Singapore. Neuropsychiatrie de l'enfance et de l'adolescence 2012;5(60):S180.

11. Nielsen K, Andria-Habermann K, Richards T, Abbott R, Mickail T, Berninger V. Emotional and behavioral correlates of persisting specific learning disabilities in written language during middle childhood and early adolescence. J Psychoeduc Assess 2018;36(7):651-69.

12. Nelson JM, Liebel SW. Socially desirable responding and college students with dyslexia: implications for the assessment of anxiety and depression. Dyslexia 2018;24(1):44-58.

13. Cameron O. Understanding Comorbid Depression and Anxiety. Psychiatric Times. 2007.

14. Mackay D. Clinical psychology: theory and therapy. Routledge; 2018.

15. Kazdin A. Encyclopedia of Psychology. 2000.

16. Silove D, Manicavasagar V, Curtis J, Blaszczynski A. Is early separation anxiety a risk factor for adult panic disorder?: a critical review. Compr Psychiatry 1996;37(3):167-79.

17. Vogel SA, Adelman PB. Success for college students with learning disabilities. New York: Springer-Verlag; 1993.

18. Ouherrou N, Elhammoumi O, Benmarrakchi F, El Kafi J. Comparative study on emotions analysis from facial expressions in children with and without learning disabilities in virtual learning environment. Educ Inform Technol 2019;24(2):1777-92.

19. Alesi M, Rappo G, Pepi, A. Depression, Anxiety at School and Self-Esteem in Children with Learning Disabilities. J Psychol Abnorm Children 2013:3(03).

20. Sati L \& Vig D. Academic Anxiety and Self-Esteem of Learning-Disabled Children. Indian J Health Wellbeing 2017:8(9):1024-6.

21. Blascovich J, Tomaka J. Measures of self esteem. Measures of Personality and Social Psychological Attitudes. 1991.

22. Peleg O. Test Anxiety, Academic Achievement, and Self-Esteem among Arab Adolescents with and without Learning Disabilities. Learning Disabil Quart 2009:32(1):11-20.

23. Vellas H. Students with Learning Disabilities and Low achieving students: Peer acceptance, Loneliness, Selfesteem and Depression. Soc Psychol Educ 1991:3(3):173-92.

24. Lyons A. Self-Esteem \& Learning Disabilities. 2012. Learning Disabilities Association of Illinois.

25. Rosenberg M. Rosenberg self-esteem scale (SES). Society and the adolescent self-image. 1965.

26. Siber \& Tippett. Outcome Measure Rosenberg Self-Esteem Scale (RSES). 1965.

27. Shorkey \& Whiteman. Outcome Measure Rosenberg Self-Esteem Scale (RSES). 1978.

28. Wallis K, Sutton D, Bassett S. Sensory modulation for people with anxiety in a community mental health setting. Occupat Ther Ment Health 2018;34(2):122-37.

29. Beck A, Epstein N, Brown G \& Steer R. An inventory for measuring clinical anxiety: Psychometric properties. J Consult Clin Psychology 1988:56(6):893-7.

30. Steer RA, Kumar G, Ranieri, WF \& Beck AT. Use of the Beck Anxiety Inventory with Adolescent Psychiatric Outpatients. Psychol Rep 1995:76(2):459-65.

31. Krefetz DG, Steer RA, Gulab NA, Beck AT. Convergent validity of the Beck Depression Inventory-II with the Reynolds Adolescent Depression Scale in psychiatric inpatients. J Personal Assess 2002;78(3):451-60.

32. Wang Y \& Gorenstein C. Psychometric properties of the Beck Depression Inventory-II: a comprehensive review. Rev Bras Psiquiatr 2013:35(4):416-31.

$* * * * * * * * * * * * * * * * * * * * * * * * * * * * *$

Acknowledgements - Nil; Conflict of Interest - Nil; Funding - Nil

Indian Journal of Mental Health 2019; 6(4) 